\title{
Modelagem do projeto da cadeia de suprimentos global: considerações teóricas e perspectivas futuras
}

\author{
Modeling the global supply chain design: theoretical discussions \\ and future perspectives
}

\author{
Monize Sâmara Visentini ${ }^{1}$ \\ Denis Borenstein ${ }^{1}$
}

\begin{abstract}
Resumo: Este artigo teórico objetiva apresentar e discutir características de modelos matemáticos de otimização do projeto da cadeia de suprimentos global, a fim de sugerir perspectivas de pesquisas futuras. A pesquisa bibliográfica foi realizada nos mais importantes periódicos internacionais de pesquisa operacional, compreendendo, predominantemente, artigos publicados entre 2000 e 2013. Dos 111 artigos selecionados, 22 foram analisados em profundidade, considerando aspectos referentes à modelagem da cadeia de suprimentos global e os fatores internacionais abordados. Através da discussão teórica, identificaram-se questões emergentes, indicando oportunidades e necessidades de desenvolvimento de novos modelos matemáticos e técnicas de solução.
\end{abstract}

Palavras-chave: Cadeia de suprimentos global. Pesquisa bibliográfica. Pesquisa operacional. Otimização.

\begin{abstract}
This theoretical paper aims to present and discuss features of mathematical optimization models for the global supply chain design in order to support future researches on this contemporary theme. The bibliographic research was performed in major international journals of Operational Research, comprising predominantly papers published between 2000 and 2013. Of the 111 papers selected, 22 were analyzed in depth considering aspects related to the modeling the global supply chain and international factors addressed. Through theoretical discussion, we identified emerging issues, indicating opportunities and needs for development of new mathematical models and solution techniques.
\end{abstract}

Keywords: Global supply chain. Bibliographic research. Operational research. Optimization.

\section{Introdução}

Com a concorrência internacional e o constante aumento da complexidade do ambiente em que operam as empresas, a gestão da cadeia de suprimentos global tem se tornado uma tarefa cada vez mais importante (RUDBERG; WEST, 2008). Entretanto, gerir cadeias de suprimento globais é incontestavelmente mais difícil do que gerir cadeias de suprimento domésticas (ou internas). Ambas lidam com fatores econômicos, como taxa de juros, preços de mercado, custos de produção e transporte, mas valores específicos são dependentes dos países envolvidos na cadeia e, portanto, é mais complexo prever esses aspectos em uma escala global (SCHMIDT; WILHELM, 2000). Enquanto a cadeia de suprimentos doméstica trata de projetos em um único país, a cadeia de suprimentos global envolve regras de comércio internacional e questões financeiras, permitindo que fornecedores, plantas e centros de distribuição (CD) estejam localizados em vários países (VIDAL; GOETSCHALCKX, 1997).
Um aspecto fundamental da cadeia de suprimentos global é que ela não avalia os custos e os lucros objetivados por uma única organização, mas de todos os envolvidos na gestão da cadeia (MENTZER; STANK; MYERS, 2007). Assim, Bassett e Gardner (2010) e Tsiakis e Papageorgiou (2008) afirmam que projetar uma cadeia de suprimentos global não é tarefa fácil, pois envolve, por exemplo: a) a seleção de instalações, de possíveis plantas em diferentes países e continentes, para cada etapa da produção e distribuição, que podem incluir decisões de investimento de capital em novas instalações ou expansões, de fechamento das instalações existentes e de seleção dos fornecedores externos; b) decisões sobre quais produtos fazer e distribuir em cada facilidade; c) decisões sobre quais mercados servir; e d) seleção das rotas da rede através dos quais os produtos devem passar para chegar ao seu destino final. Dada a amplitude dos aspectos envolvidos, Fandel e Stammen (2004) ressaltam que a capacidade

\footnotetext{
${ }^{1}$ Programa de Pós-graduação em Administração, Universidade Federal do Rio Grande do Sul - UFRGS, Rua Washington Luiz, 855, Centro, CEP 90010-460, Porto Alegre, RS, Brasil, e-mail: monize.s.visentini@gmail.com; denisb@ea.ufrgs.br.
}

Recebido em 1/4/2012 — Aceito em 14/7/2013

Suporte financeiro: Capes e CNPq. 
de definir e resolver modelos de otimização da cadeia de suprimentos global torna-se uma tarefa importante do planejamento estratégico das organizações.

Este artigo tem como objetivo apresentar e discutir características de modelos de otimização para o projeto da cadeia de suprimentos global (as expressões "projeto da cadeia de suprimentos global" e "desenho da cadeia de suprimentos global" são utilizadas como sinônimos neste artigo), a fim de sugerir possíveis caminhos para pesquisas futuras. $\mathrm{O}$ interesse por essa abordagem recai sobre dois aspectos: o primeiro referente ao baixo número de levantamentos teóricos acerca do tema, trabalhos esses que contribuem para identificar lacunas no campo de investigação; e o segundo referente a relevância e atualidade dessa abordagem para a área de logística. Cabe ressaltar que o levantamento bibliográfico realizado não se configura como um estado-da-arte acerca da temática investigada, mas aborda discussões e aspectos interessantes e promissores para estudos futuros, a partir da busca nos principais periódicos internacionais de pesquisa operacional e áreas afins.

Para extrair os aspectos-chave de cada trabalho revisado, a análise abrangeu, em especial, os fatores internacionais da cadeia de suprimentos global, visto que eles são diferenciais dessa cadeia com relação à doméstica e atuam como abordagem promissora para novas investigações. Além disso, Verter e Dincer (1995a) identificaram que poucos estudos têm incluído aspectos internacionais nos modelos estratégicos de produção-distribuição na cadeia global. Os autores também revisaram a literatura acerca das questões estratégicas para a cadeia de suprimentos global e concluíram que existe um número limitado de modelos que aborda questões internacionais, recomendando que pesquisas futuras desenvolvam métodos mais eficientes para prescrever melhores configurações (VERTER; DINCER, 1995b).

Este artigo está estruturado da seguinte forma: na seção 2 são apresentados os procedimentos metodológicos adotados; na seção 3 é realizada a análise dos resultados, que compreende a descrição e discussão dos artigos selecionados; e na seção 4 são feitas as considerações finais e sugeridas novas possibilidades de pesquisa a partir das análises realizadas.

\section{Procedimentos metodológicos para a seleção dos artigos}

O método de pesquisa utilizado para realizar o levantamento bibliográfico seguiu algumas das etapas sugeridas por Tezza, Bornia e Vey (2010). Na primeira delas, definiu-se a base de dados na qual seria realizado o levantamento dos artigos. Selecionou-se, então, a base Web of Science ${ }^{\circledR}$, visto que nela são disponibilizados mais de 12 mil periódicos internacionais e regionais e uma série de livros em todas as áreas das ciências naturais e sociais, bem como em artes e humanidades (TESTA, 2009). Para comprovar a adequação dos periódicos disponíveis na Web of Science ${ }^{\circledR}$ aos objetivos deste estudo, analisou-se se nela estavam indexadas as 39 revistas científicas citadas por Olson (2005) como as de maior visibilidade na pesquisa operacional e áreas correlatas, bem como os periódicos mencionados por Meixell e Gargeya (2005) como sendo os principais da administração e pesquisa operacional. Como resultado, verificou-se que mais de $80 \%$ dos periódicos sugeridos por Olson (2005) e Meixell e Gargeya (2005) estão disponíveis nessa base. Cabe ressaltar que também foram realizadas buscas em periódicos nacionais que não estavam indexados na Web of Science ${ }^{\circledR}$ mas que não foram encontrados artigos com enfoque no projeto da cadeia de suprimentos global.

Na segunda etapa do processo fez-se a seleção das referências, englobando artigos publicados entre os anos 2000 e 2013 que possuíssem no resumo as seguintes palavras fixas supply chain ou supply network, aliadas à design ou optimization, e as seguintes palavras variáveis, que eram combinadas com as duplas de palavras fixas: transfer price ou duty/duties ou exchange ou export ou import ou international trade ou tariffs ou modeling. $\mathrm{O}$ intervalo de tempo escolhido para a seleção dos artigos derivou de indicações encontradas em Meixell e Gargeya (2005) de que, a partir da década de 2000, os modelos de projeto da cadeia de suprimentos global passaram a ampliar o escopo de aspectos internacionais considerados e implantar abordagens multiperíodo mais frequentemente, características de relevância para a discussão proposta neste trabalho.

A busca de referências resultou em 111 artigos, que foram cuidadosamente analisados para identificar aqueles que se enquadravam na proposta. Alguns foram descartados a partir da leitura do respectivo resumo, visto que estavam totalmente em desacordo com a temática investigada. Para os demais, dentre os aspectos analisados estavam o tipo de cadeia de suprimentos estudada (global ou doméstica), o tipo de modelagem do projeto da cadeia de suprimentos, o uso de técnicas de pesquisa operacional para solução do problema e a natureza dos parâmetros utilizados (determinísticos ou estocásticos). Salienta-se que foram selecionados apenas modelos determinísticos, pois segundo Wilhelm et al. (2005), essa é a configuração predominante nos trabalhos de modelagem do desenho da cadeia de suprimentos, visto que neles é possível prever a maioria dos dados e eventos futuros com um grau de certeza suficiente (CREAZZA; DALLARI; ROSSI, 2012). Sugere-se como leitura o trabalho de Baghalian, Rezapour e Farahani (2013), em que é apresentada uma revisão bibliográfica detalhada de modelos estocásticos que otimizam o projeto das 
cadeias de suprimentos. Ao final da avaliação dos artigos, elencaram-se 20 trabalhos que contemplam todos os critérios definidos.

Seguindo a proposta de Tezza, Bornia e Vey (2010), na etapa final buscou-se a seleção de novos documentos com o intuito de identificar, nas referências bibliográficas dos artigos previamente selecionados, os mais citados, com o objetivo de inseri-los na classificação. Assim, incluiram-se os trabalhos de Katayama (1999) e Arntzen et al. (1995), esse amplamente referenciado devido as suas contribuições à otimização da cadeia de suprimentos global, visto que possui um dos mais abrangentes modelos publicados durante a década de 1990 (VIDAL; GOETSCHALCKX, 1997; OH; KARIMI, 2006), fornecendo importante contribuição para o desenvolvimento do campo (DAS; SENGUPTA, 2009).

O Quadro 1 descreve os autores e periódicos dos 22 artigos selecionados pela base Web of Science ${ }^{\circledR}$, indicando os periódicos que foram referenciados nos trabalhos de Meixell e Gargeya (2005) e Olson (2005), bem como os respectivos fatores de impacto.

Quadro 1. Descrição dos artigos pesquisados.

\begin{tabular}{|c|c|c|c|c|}
\hline Autores/Ano & Periódico & $\begin{array}{c}\text { Meixell e } \\
\text { Gargeya (2005) }\end{array}$ & $\begin{array}{l}\text { Olson } \\
(2005) \\
\end{array}$ & $\begin{array}{l}\text { Fator de } \\
\text { impacto }^{1}\end{array}$ \\
\hline Arntzen et al. (1995) & Interfaces & $\mathrm{x}$ & $\mathrm{x}$ & 0.843 \\
\hline Katayama (1999) & $\begin{array}{l}\text { International Journal of Operations } \\
\text { \& Production Management }\end{array}$ & $\mathrm{x}$ & $\mathrm{x}$ & 1.127 \\
\hline Vidal e Goetschalckx (2001) & $\begin{array}{l}\text { European Journal of Operational } \\
\text { Research }\end{array}$ & $\mathrm{x}$ & $\mathrm{x}$ & 1.815 \\
\hline Fandel e Stammen (2004) & $\begin{array}{l}\text { International Journal of Production } \\
\text { Economics }\end{array}$ & $\mathrm{x}$ & $\mathrm{x}$ & 1.760 \\
\hline Wilhelm et al. (2005) & $\begin{array}{l}\text { Transportation Research Part E: } \\
\text { Logistics and Transportation Review }\end{array}$ & $\mathrm{x}$ & & 1.648 \\
\hline Oh e Karimi (2006) & AIChE Journal & & & 2.261 \\
\hline Vila, Martel e Beauregard (2006) & $\begin{array}{l}\text { International Journal of Production } \\
\text { Economics }\end{array}$ & $\mathrm{x}$ & $\mathrm{x}$ & 1.760 \\
\hline Balaji e Viswanadham (2008) & $\begin{array}{l}\text { IEEE Transactions on Automation } \\
\text { Science and Engineering }\end{array}$ & & & 1.461 \\
\hline Tsiakis e Papageorgiou (2008) & $\begin{array}{l}\text { International Journal of Production } \\
\text { Economics }\end{array}$ & $\mathrm{x}$ & $\mathrm{x}$ & 1.760 \\
\hline Villegas e Ouenniche (2008) & $\begin{array}{l}\text { European Journal of Operational } \\
\text { Research }\end{array}$ & $\mathrm{x}$ & $\mathrm{x}$ & 1.815 \\
\hline Das e Sengupta (2009) & $\begin{array}{l}\text { International Journal of Production } \\
\text { Economics }\end{array}$ & $\mathrm{x}$ & $\mathrm{x}$ & 1.760 \\
\hline ElMaraghy e Mahmoudi (2009) & $\begin{array}{l}\text { International Journal of Computer } \\
\text { Integrated Manufacturing }\end{array}$ & $\mathrm{x}$ & & 1.071 \\
\hline Feng e Wu (2009) & $\begin{array}{l}\text { International Journal of Production } \\
\text { Economics }\end{array}$ & $\mathrm{x}$ & $\mathrm{x}$ & 1.760 \\
\hline Bassett e Gardner (2010) & Computers \& Chemical Engineering & & & 2.320 \\
\hline Perron et al. (2010) & $\begin{array}{l}\text { European Journal of Operational } \\
\text { Research }\end{array}$ & $\mathrm{x}$ & $\mathrm{x}$ & 1.815 \\
\hline Wu (2010) & Computers \& Industrial Engineering & & $\mathrm{x}$ & 1.589 \\
\hline $\begin{array}{l}\text { Papapostolou, Kondili } \\
\text { e Kaldellis (2011) }\end{array}$ & Energy & & & 3.487 \\
\hline Sousa et al. (2011) & $\begin{array}{l}\text { Chemical Engineering Research and } \\
\text { Design }\end{array}$ & & & 1.968 \\
\hline Creazza, Dallari e Rossi (2012) & $\begin{array}{l}\text { International Journal of Production } \\
\text { Research }\end{array}$ & & $\mathrm{x}$ & 1.115 \\
\hline Singh et al. (2012) & $\begin{array}{l}\text { The International Journal of } \\
\text { Advanced Manufacturing Technology }\end{array}$ & & & 1.103 \\
\hline Susarla e Karimi (2012) & Computers \& Chemical Engineering & & & 2.320 \\
\hline Bassett e Gardner (2013) & Annals of Operations Research & & $\mathrm{x}$ & 0.840 \\
\hline
\end{tabular}

${ }^{1}$ Fator de impacto (2011 JCR Science Edition). Disponível em: http://admin-apps.webofknowledge.com/JCR/ JCR?RQ=LIST_SUMMARY_JOURNAL 
Nota-se que alguns dos periódicos selecionados não se encontram na classificação de Meixell e Gargeya (2005) e Olson (2005), visto que não são especificamente da área de pesquisa operacional, mas possibilitam a divulgação de estudos correlatos à modelagem da cadeia de suprimentos global, como os periódicos das áreas de Economia e Química indexados na Web of Science ${ }^{\circledR}$, motivo pelo qual optou-se por analisá-los. Adicionalmente, a fim de garantir a qualidade desses periódicos, analisou-se o Fator de Impacto, uma medida que possibilita avaliar a "qualidade de uma publicação verificando o nível de interesse dos outros pela pesquisa" (MEADOWS, 1999, p. 89 apud STREHL, 2005) mensurada com base na quantidade de citações dessa pesquisa na bibliografia subsequente. Essa medida também é utilizada a nível nacional pelo sistema de avaliação de qualidade da publicação (QUALIS), divulgado pela CAPES (Coordenação de Aperfeiçoamento de Pessoal de Nível Superior), e é relativizada por áreas. Nas áreas de Administração, Ciências Contábeis, Turismo e Engenharias, os periódicos indexados no Institute for Scientific Information (ISI) com fator de impacto publicado no Journal Citation Reports (JCR) igual ou superior a 0.5 são considerados de excelente qualidade, característica de todos os periódicos apresentados no Quadro 1.

\section{Análise de modelos para o projeto da cadeia de suprimentos global}

Nesta seção são discutidas as características dos modelos matemáticos presentes nos artigos selecionados, que objetivam otimizar o projeto da cadeia de suprimentos global. A primeira análise é a da função objetivo de cada um dos modelos. Na sequência faz-se uma comparação entre as variáveis de decisão e os parâmetros adotados. A análise posterior recai sobre aspectos gerais, como a abordagem de modelagem e de solução, o horizonte de planejamento, o número de níveis da cadeia de suprimentos considerados e o contexto industrial no qual foi (ou não) aplicado o modelo. Por fim, faz-se um levantamento dos aspectos internacionais considerados, característica particular da cadeia de suprimentos global.

\subsection{Função objetivo}

No Quadro 2 são descritos os artigos analisados, bem como o objetivo de cada modelo, e a classificação da função objetivo como maximizar lucro ou minimizar custos.

Percebe-se que a maioria dos recentes modelos analisados visa maximizar lucros após os impostos, contrastando com achados anteriores (VIDAL; GOETSCHALCKX, 1997; MELO; NICKEL; SALDANHA-DA-GAMA, 2009; MULA et al., 2010), o que pode indicar uma mudança gradativa nas medidas de performance da cadeia de suprimentos global. Melo, Nickel e Saldanha-da-Gama (2009) salientam que essa é a escolha mais lógica (maximizar lucros) para otimizar o projeto da cadeia de suprimentos, visto que as decisões nesse âmbito envolvem grandes somas monetárias e os investimentos são geralmente avaliados com base na sua taxa de retorno.

Ao realizar uma revisão crítica dos modelos estratégicos de produção-distribuição na cadeia de suprimentos global, Vidal e Goetschalckx (1997) identificaram um número superior de modelos com o objetivo minimizar custos ao invés de maximizar lucros. No recente trabalho de Mula et al. (2010), que faz uma revisão de modelos de programação matemática para produção e transporte da cadeia de suprimentos, também foi identificada a minimização dos custos totais como o principal propósito, enquanto a maximização de receitas e vendas é considerada em menor extensão. Nessa mesma direção, Melo, Nickel e Saldanha-da-Gama (2009), ao revisarem modelos de localização de instalações na cadeia de suprimentos, identificaram que $75 \%$ dos modelos objetivam minimizar o custo total da rede e apenas $16 \%$ mensuravam a maximização dos lucros. Segundo esses autores, tal achado é surpreendente, pois a maioria das atividades comerciais visa fins lucrativos.

A lógica da escolha de maximização dos lucros está relacionada ao fato de que nem sempre é atraente para as empresas satisfazer todas as necessidades dos clientes, o que incorreria em custos adicionais às receitas correspondentes; além disso, uma empresa pode, intencionalmente, perder clientes quando os custos de sua manutenção são proibitivos (MELO; NICKEL; SALDANHA-DA-GAMA, 2009).

Dos trabalhos apresentados no Quadro 2, os de Arntzen et al. (1995), Das e Sengupta (2009) e Bassett e Gardner (2010, 2013) possuem diferentes classificações dos objetivos. Arntzen et al. (1995) consideram múltiplos períodos de tempo para otimizar a cadeia de suprimentos global, diferenciando seu modelo dos demais por incorporar na função objetivo o impacto dos longos tempos de trânsito em termos de custo. A função objetivo visa à minimização das variáveis custos de estoques, custos de transporte e custos de produção, menos os abatimentos de suspensão ou isenção do recolhimento de impostos e taxas de importação (drawbacks). Os aspectos relacionados à atividade da cadeia de suprimento são ponderados por um fator $\alpha$ na função objetivo, referente ao tempo necessário para realizar uma atividade individual de produção ou distribuição.

Das e Sengupta (2009) apresentam um problema em dois níveis, variando a função objetivo conforme o nível de análise da cadeia de suprimentos global. O primeiro nível, o estratégico, identifica a localização e a seleção das instalações, quantidade por tipo de 
Quadro 2. Artigos analisados e respectiva função objetivo.

\begin{tabular}{|c|c|c|}
\hline Autores/Ano & Objetivo & Classificação \\
\hline Arntzen et al. (1995) & $\begin{array}{l}\text { A função objetivo é uma composição de custo e } \\
\text { tempo. }\end{array}$ & $\begin{array}{l}\text { minimizar custos e/ } \\
\text { ou tempo de atividade } \\
\text { ponderado }\end{array}$ \\
\hline Katayama (1999) & $\begin{array}{l}\text { Minimizar o custo total de implantação de uma } \\
\text { cadeia de suprimentos global. }\end{array}$ & minimizar custos \\
\hline Vidal e Goetschalckx (2001) & $\begin{array}{l}\text { Maximizar o lucro líquido de uma corporação } \\
\text { multinacional e incluir o preço de transferência e a } \\
\text { alocação dos custos de transporte como variáveis de } \\
\text { decisão explícitas. }\end{array}$ & $\begin{array}{l}\text { maximizar lucro depois } \\
\text { dos impostos }\end{array}$ \\
\hline Fandel e Stammen (2004) & $\begin{array}{l}\text { Maximizar a soma dos lucros após impostos em } \\
\text { vários períodos de tempo. }\end{array}$ & $\begin{array}{l}\text { maximizar lucro depois } \\
\text { dos impostos }\end{array}$ \\
\hline Wilhelm et al. (2005) & Maximizar lucro depois dos impostos. & $\begin{array}{l}\text { maximizar lucro depois } \\
\text { dos impostos }\end{array}$ \\
\hline Oh e Karimi (2006) & $\begin{array}{l}\text { Maximizar o total de lucros após impostos ao longo } \\
\text { do horizonte de planejamento. }\end{array}$ & $\begin{array}{l}\text { maximizar lucro depois } \\
\text { dos impostos }\end{array}$ \\
\hline Vila, Martel e Beauregard (2006) & Maximizar lucro líquido global após impostos. & $\begin{array}{l}\text { maximizar lucro depois } \\
\text { dos impostos }\end{array}$ \\
\hline Balaji e Viswanadham (2008) & $\begin{array}{l}\text { Minimizar os custos de produção e estoques } \\
\text { associados aos custos dos estágios }{ }^{1} \text { e do transporte e } \\
\text { (minimizar) impostos associados entre os estágios. }\end{array}$ & minimizar custos \\
\hline Tsiakis e Papageorgiou (2008) & $\begin{array}{l}\text { Minimizar os custos totais anuais da rede tendo } \\
\text { em conta tanto os custos operacionais quanto os de } \\
\text { infraestrutura. }\end{array}$ & minimizar custos \\
\hline Villegas e Ouenniche (2008) & $\begin{array}{l}\text { Maximizar os lucros repatriados (vindos de divisões } \\
\text { estrangeiras) após os impostos. }\end{array}$ & $\begin{array}{l}\text { maximizar lucro depois } \\
\text { dos impostos }\end{array}$ \\
\hline Das e Sengupta (2009) & $\begin{array}{l}\text { Nível 1) Estratégico: maximizar lucro; } \\
\text { Nível 2) Operacional: minimizar o custo de estoque } \\
\text { no CD. }\end{array}$ & $\begin{array}{l}\text { nível 1) estratégico: } \\
\text { maximizar lucro; nível 2) } \\
\text { operacional: minimizar o } \\
\text { custo de estoque }\end{array}$ \\
\hline ElMaraghy e Mahmoudi (2009) & $\begin{array}{l}\text { Minimizar os custos totais da cadeia de suprimentos } \\
\text { global ao longo do tempo. }\end{array}$ & minimizar custos \\
\hline Feng e Wu (2009) & $\begin{array}{l}\text { Maximizar os lucros globais após os impostos na } \\
\text { cadeia de suprimentos global. }\end{array}$ & $\begin{array}{l}\text { maximizar lucro depois } \\
\text { dos impostos }\end{array}$ \\
\hline Bassett e Gardner (2010) & $\begin{array}{l}\text { Otimizar o desenho e o cronograma de uma cadeia } \\
\text { de suprimentos global para maximizar os lucros. }\end{array}$ & $\begin{array}{l}\text { maximizar lucro de uma } \\
\text { família de produtos }\end{array}$ \\
\hline Perron et al. (2010) & $\begin{array}{l}\text { Maximizar o lucro global de uma corporação } \\
\text { multinacional depois dos impostos, determinando o } \\
\text { fluxo de mercadorias, os preços de transferência e o } \\
\text { custo de alocação de transporte entre cada uma das } \\
\text { suas subsidiárias. }\end{array}$ & $\begin{array}{l}\text { maximizar lucro depois } \\
\text { dos impostos }\end{array}$ \\
\hline Wu (2010) & $\begin{array}{l}\text { Atender a demanda do mercado com custo total } \\
\text { mínimo. }\end{array}$ & minimizar custos \\
\hline $\begin{array}{l}\text { Papapostolou, Kondili } \\
\text { e Kaldellis (2011) }\end{array}$ & Maximizar lucro líquido global após impostos. & $\begin{array}{l}\text { maximizar lucro depois } \\
\text { dos impostos }\end{array}$ \\
\hline Sousa et al. (2011) & Maximizar lucro líquido global após impostos. & $\begin{array}{l}\text { maximizar lucro depois } \\
\text { dos impostos }\end{array}$ \\
\hline Creazza, Dallari e Rossi (2012) & Minimizar os custos anuais de operação. & minimizar custos \\
\hline Singh et al. (2012) & Minimizar os custos totais de operação. & minimizar custos \\
\hline Susarla e Karimi (2012) & Maximizar lucro líquido global após impostos. & $\begin{array}{l}\text { maximizar lucro depois } \\
\text { dos impostos }\end{array}$ \\
\hline Bassett e Gardner (2013) & $\begin{array}{l}\text { Otimizar o desenho e o cronograma de uma cadeia } \\
\text { de suprimentos global para maximizar os lucros. }\end{array}$ & $\begin{array}{l}\text { maximizar lucro de uma } \\
\text { família de produtos }\end{array}$ \\
\hline
\end{tabular}

${ }^{1}$ Cada estágio representa uma atividade, tais como produção, montagem, transporte, distribuição ou varejo. 
produto a ser fabricado ou importado, as quantidades fabricadas ou importadas enviadas para os CDs e a atribuição de CDs para clientes a fim de satisfazer a demanda de mercado. O objetivo desse problema é maximizar o lucro da unidade de negócio, baseado no preço do produto no mercado e nos custos relevantes. $\mathrm{O}$ segundo nível, o operacional, estabelece questões que incluem estoque de segurança e canais de distribuição e transporte para o cliente. A função objetivo minimiza os custos de estoque nos CDs, considerando a demanda incerta dos clientes, o custo médio do produto, o lead time incerto para transportar produtos da instalação (planta) para os CDs.

Conforme Melo, Nickel e Saldanha-da-Gama (2009), duas categorias diferentes de maximização do lucro são observadas na literatura, como se segue: (i) a maximização das receitas menos despesas, e (ii) a maximização do lucro depois dos impostos. Analisando-se o Quadro 2, somente Bassett e Gardner $(2010,2013)$ utilizam a maximização das receitas. Esses modelos visam maximizar o lucro total de uma família de produtos agrícolas que circulam em uma cadeia de suprimentos global de três níveis usando como moeda de referência dólares americanos. Dadas as características dos produtos que transitam na cadeia, de vida útil menor, o seu projeto e programação são normalmente otimizados por um mês, num horizonte temporal de um ou dois anos, com base na previsão de demanda.

Vidal e Goetschalckx (2001) desenvolvem um modelo para resolver problemas de uma empresa multinacional o qual maximiza os lucros após os impostos globais através da determinação do fluxo de mercadorias, dos preços de transferência e dos custos de alocação do transporte entre cada um dos atores da cadeia. Esse problema de otimização possui função objetivo linear, um grupo de restrições lineares e um de restrições bilineares. As restrições bilineares são referentes ao lucro líquido antes dos impostos de cada subsidiária - nelas, cada termo corresponde ao produto de duas variáveis de decisão, que representam o fluxo de mercadorias e o preço de transferência entre duas subsidiárias - e ao produto do fluxo de mercadorias e das variáveis de alocação de custos de transporte. Os termos bilineares são linearizados para a resolução do modelo, que é classificado como NP-hard.

Perron et al. (2010) reformulam o modelo de Vidal e Goetschalckx (2001). A função objetivo e grande parte das restrições são as mesmas do modelo original. Uma das modificações realizadas refere-se aos termos bilineares do produto do fluxo de mercadorias e das variáveis de alocação de custos de transporte. Perron et al. (2010) eliminam esses termos, considerando que o custo total de transporte entre duas subsidiárias é dividido entre elas e, depois de introduzir novas variáveis, o termo bilinear correspondente é removido. Assim, o custo total de transporte entre duas subsidiárias pode ser calculado como a soma do custo de transporte de cada uma delas.

O modelo de Fandel e Stammen (2004) diferencia-se dos demais ao considerar custos de desenvolvimento e de reciclagem e capacidades. O objetivo da abordagem é otimizar os lucros após impostos. Esse modelo, na opinião de Vila, Martel e Beauregard (2006), juntamente com o de Arntzen et al. (1995), é um dos mais abrangentes sobre a cadeia de suprimentos global, visto que aborda, além de relevantes aspectos internacionais, o ciclo de vida do produto.

O modelo de Wilhelm et al. (2005) visa fornecer auxílio à tomada de decisão estratégica de empresas inseridas em um ambiente de negócios internacional EUA-México, criado pelo Nafta. O objetivo é maximizar lucros após impostos. Integra-se às decisões estratégicas do modelo a preocupação de atender as exigências dos clientes sem atraso, o que eliminaria custos adicionais. O modelo de Oh e Karimi (2006) também é de nível estratégico, buscando maximizar os lucros totais de uma companhia multinacional após impostos ao longo do tempo, através de um programa linear que considera prioritariamente a influência dos custos de drawback. A formulação é sucinta e dois cenários diferentes (com e sem drawbacks) são analisados para testar computacionalmente o modelo, resolvido com apoio do software IBM Ilog CPLEX 9.0 em no máximo 30 segundos.

Vila, Martel e Beauregard (2006) fornecem uma metodologia genérica para o projeto de uma rede internacional de produção-distribuição para produtos com processo de produção diferenciada. O objetivo é maximizar o lucro global depois dos impostos. Para ilustração, os autores utilizam o caso real da cadeia de suprimentos global de uma indústria madeireira canadense. Nesse modelo, decisões estratégicas são implementadas no início do horizonte de planejamento mas outras decisões (táticas/operacionais), como a alocação de demanda dos clientes às instalações, podem variar ao longo do tempo. Isso é devido à natureza dos produtos envolvidos na cadeia de suprimentos, que possibilitam à indústria atualizar os pedidos solicitados pelos clientes.

Villegas e Ouenniche (2008) buscam maximizar os lucros repatriados (vindos de divisões estrangeiras) após os impostos através de uma formulação matemática irrestrita. Feng e Wu (2009) estruturam um modelo a partir dos propostos por Vidal e Goetschalckx (2001), Fandel e Stammen (2004) e Vila, Martel e Beauregard (2006). A função objetivo maximiza o lucro global e auxilia na determinação da melhor rota para a economia fiscal e o processo de fabricação de cada encomenda/lote. Papapostolou, Kondili e Kaldellis (2011) implementam um modelo matemático para a maximização dos lucros de uma cadeia integrada de biodiesel localizada na Grécia. 
Devido às características dessa cadeia, que passa por mudanças de configuração bastante rápidas, no modelo são incorporados aspectos relativos a diferentes níveis, como (re)alocação de instalações, seleção de matérias-primas, políticas comerciais internacionais, preços de venda, financiamentos e quantidades a serem importadas e/ou exportadas.

Sousa et al. (2011) desenvolvem um modelo dinâmico de alocação e planejamento da cadeia de suprimentos de companhias farmacêuticas multinacionais, mas sem abordar uma empresa específica e sim as características da cadeia de suprimentos desse tipo de negócio. O objetivo do modelo é maximizar o lucro líquido da empresa, sendo considerados na função objetivo diferentes custos, como os de produção, de transporte, de manuseio de estoque, de alocação de produtos, de demanda não atendida e de impostos e as receitas oriundas de vendas. Como grandes instâncias não são resolvidas em tempo razoável na otimalidade, os autores utilizam dois algoritmos de decomposição que apresentaram resultados satisfatórios. Também considerando a indústria farmacêutica, Susarla e Karimi (2012) elaboram um modelo que integra a aquisição, produção e distribuição da cadeia com aspectos fiscais internacionais, estoques e custos de tratamento e eliminação dos resíduos industriais. Dois cenários com instâncias de grande porte são testados e indicam eficiência da proposta, que possibilita a maximização dos lucros da cadeia após os impostos em um tempo de solução computacional razoável, cerca de 300 segundos.

Com relação aos modelos que visam minimizar os custos da cadeia de suprimentos global, tem-se o de Katayama (1999), que elabora um modelo de programação linear inteira para projetar uma cadeia de suprimentos global na região ASEAN-China. Nele são abordados custos de produção de peças específicas em cada país, custos de transporte e tarifas pagas em operações de importação/exportação. Já Balaji e Viswanadham (2008) desenvolvem, a partir de um modelo ponderado, um modelo fiscal integrado. No modelo ponderado, a função objetivo busca a minimização dos custos, levando em consideração a soma dos custos de produção, de estoque e de transporte, sendo cada um desses custos multiplicado por um fator de ponderação. O modelo fiscal integrado incorpora taxas ao modelo, multiplicadas por um fator de ponderação. Esse modelo objetiva minimizar os custos de produção e estoque associados com os impostos entre os estágios (produção, montagem, transporte, distribuição ou varejo) e os custos de transporte. O problema classifica-se como NP-hard, através de uma redução polinomial utilizando o problema da mochila com múltipla escolha. A complexidade computacional do mesmo é reduzida através do transporte da produção em estágios, passando por centrais, o que é classificado como "terceirização baseada em centrais" (hub-based sourcing). O modelo fiscal integrado foi linearizado através da introdução de centrais (hubs) em cada estágio da cadeia.

Tsiakis e Papageorgiou (2008) buscam minimizar os custos totais anuais da rede considerando tanto os custos operacionais quanto os de infraestrutura. Para demonstrar a aplicabilidade do modelo, analisa-se o desempenho de uma indústria do setor químico em uma cadeia que se estende por países de vários continentes, onde são aplicadas diferentes moedas e taxas. O modelo de ElMaraghy e Mahmoudi (2009) tem por objetivo minimizar os custos totais da cadeia ao longo do tempo. A sua aplicação é avaliada usando dados históricos de um fabricante de limpadores de motor para automóveis. Wu (2010) busca minimizar o custo total de produção.

Dentre os trabalhos mais recentes estão o de Creazza, Dallari e Rossi (2012) e o de Singh et al. (2012). No primeiro é proposto um modelo integrado para o projeto e otimização da cadeia global que visa minimizar custos anuais de operação. O diferencial desse modelo é a amplitude da função objetivo, que contempla diversos tipos de custos, como o decorrido da distância entre as instalações, das quantidades transportadas, das quantidades demandadas, das quantidades estocadas, custos de manutenção, entre outros aspectos de uma rede logística. Outro aspecto inovador do trabalho é a seção de mapeamento de dados, na qual são fornecidas orientações metodológicas para a coleta e o processamento dos dados necessários para configurar o modelo. Singh et al. (2012) focam na identificação dos diferentes níveis de risco e seus efeitos sobre o funcionamento da cadeia de suprimentos com o objetivo de minimizar o custo total de operação. Dentre os fatores de risco incorporados ao modelo estão: taxas de câmbio, atraso no carregamento dos produtos, problemas de qualidade, logística e transporte. Todos os riscos relacionados são matematicamente formulados como custos adicionais na cadeia de suprimentos.

\subsection{Variáveis de decisão e parâmetros dos modelos analisados}

O Quadro 3 apresenta as variáveis de decisão e os parâmetros mais frequentemente encontrados nos modelos analisados. A fim de facilitar a análise, as variáveis de decisão foram categorizadas em grupos, sendo um deles o de variáveis binárias $(0,1)$, que abrangem as decisões de seleção de fornecedor, instalação e/ou centro de distribuição (CD) e de alocação de produto nas instalações ou CD. O outro grupo de análise compreende as demais variáveis de decisão (binárias, inteiras e contínuas) e os parâmetros 


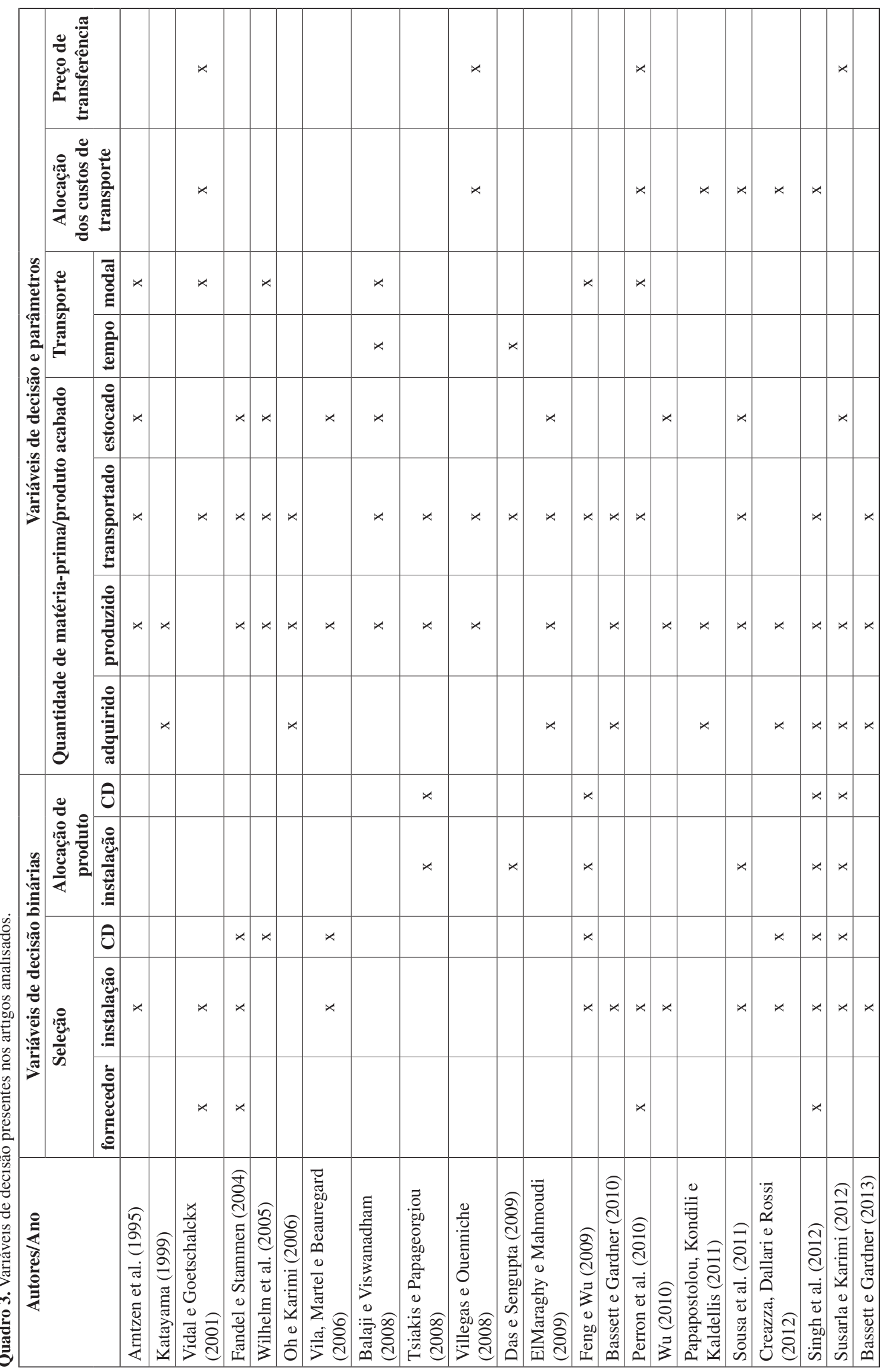


utilizados como entrada de dados para a resolução do problema. Nesse grupo são elencadas a quantidade de matéria-prima adquirida e a quantidade de produto acabado (em unidades) produzido nas fábricas, transportado entre as subsidiárias e para os clientes, e estocado; transporte, abrangendo tempo de transporte (tempo de deslocamento) do produto acabado entre subsidiárias e clientes e a seleção de modais de transporte a serem utilizados; custos de transporte e preço de transferência.

Dentre as variáveis binárias de decisão de seleção de fornecedor, instalação e/ou centro de distribuição (CD), observa-se a predominância da variável seleção de instalação, geralmente distribuídas por diferentes países pertencentes à cadeia de suprimentos global. Alguns modelos consideram essa variável em conjunto com a decisão seleção de CD (FANDEL; STAMMEN, 2004; VILA; MARTEL; BEAUREGARD, 2006; FENG; WU, 2009; CREAZZA; DALLARI; ROSSI, 2012; SINGH et al., 2012; SUSARLA; KARIMI, 2012). Os modelos de Fandel e Stammen (2004) e Singh et al. (2012) são os únicos que abarcam as decisões de seleção de fornecedor, de instalação e de CD. Em Fandel e Stammen (2004) foca-se nas decisões relativas ao ciclo de vida do produto, através dos processos de desenvolvimento de produtos e reciclagem. Assim, variáveis de decisão como a alocação dos produtos reciclados entre os centros de reciclagem (também distribuídos globalmente) e a quantidade de produtos reciclados por centro de reciclagem são incorporadas ao modelo, bem como as quantidades de produto acabado, transportado e estocado. Já Singh et al. (2012), além de apresentarem um modelo abrangente em número de variáveis e parâmetros, também incluem variáveis de decisão referentes ao risco das operações da cadeia de suprimentos.

As variáveis binárias de alocação de produto estão presentes em apenas seis modelos (TSIAKIS; PAPAGEORGIOU, 2008; DAS; SENGUPTA, 2009; FENG; WU, 2009; SOUSA et al., 2011; SINGH et al., 2012; SUSARLA; KARIMI, 2012), sendo que Tsiakis e Papageorgiou (2008), Singh et al. (2012) e Susarla e Karimi (2012) consideram decisões de atribuição de produto para determinada fábrica e $\mathrm{CD}$. Em Tsiakis e Papageorgiou (2008) são acrescidas ainda decisões de nível de produção, fluxo de produtos transferidos do $\mathrm{CD}$ para atender os clientes já fixados em diferentes continentes e capacidade dos CDs. A aplicação desse modelo proporciona um melhor aproveitamento das instalações, seleção de portfólios de produtos adequados, economia no transporte total e nos impostos.

Dentre a categoria de quantidade de produto acabado, têm-se as variáveis de decisão e/ou parâmetros quantidade de produto acabado produzido e quantidade de produto acabado transportado (entre as subsidiárias; entre as instalações e os CDs; entre os CDs e os clientes) como as mais frequentemente encontradas nos modelos analisados, sendo que pelo menos uma delas está presente em todos os modelos. Em Vidal e Goetschalckx (2001), Das e Sengupta (2009) e Perron et al. (2010) somente foi utilizada a quantidade de produto acabado transportado. Já o modelo de Oh e Karimi (2006) acrescenta também a quantidade de matéria-prima adquirida e decisões de terceirizar ou não a produção. Cabe ressaltar que esse modelo e o de Balaji e Viswanadham (2008) são os únicos que abordam decisões de terceirização na cadeia de suprimentos global. Papapostolou, Kondili e Kaldellis (2011) focam nas quantidades de matéria-prima adquiridas do mercado interno e nas quantidades cultivadas ou importadas, identificando a melhor alternativa viável para a otimização do projeto e das operações da cadeia do biodiesel.

O modelo de ElMaraghy e Mahmoudi (2009) é o mais completo no que tange à decisão de quantidade, inserindo decisões de quantidade de matériaprima adquirida, quantidade de produto acabado produzido, transportado e estocado. Variáveis de decisão adicionais como a quantidade de produto em trânsito entre a fábrica e o CD e o total de horas extras e horas regulares dos funcionários na fábrica também são consideradas. Uma limitação desse modelo consiste em assumir que a quantidade demandada e o lead-time de produção e transporte são fixos, ignorando a natureza estocástica desses fatores. Ao incluir as respectivas distribuições de probabilidade, pode-se incrementar a qualidade do modelo proposto.

No que tange à inclusão de tempo de transporte e modais de transporte, tem-se somente o modelo de Balaji e Viswanadham (2008), que as utiliza em conjunto. Nesse modelo, a variável decisão de transporte entre dois estágios de produção é expressa como uma função do estágio de aquisição ou estoque de um produto e a variável decisão associada ao modal de transporte utilizado. Essas variáveis tornam-se essenciais no modelo, por abrangerem a terceirização da produção. Assim, cada etapa tem um custo de produção e estoque. No caso da produção própria, os custos de capital são absorvidos pelo custo de produção; no caso da terceirização, o custo de produção é equivalente ao custo de aquisição. Além desse modelo, somente o de Das e Sengupta (2009) considera o tempo de transporte como variável de decisão.

Já as variáveis de decisão de modais de transporte são incorporadas por um número maior de estudos (ARNTZEN et al., 1995; VIDAL; GOETSCHALCKX, 2001; WILHELM et al., 2005; BALAJI; VISWANADHAM, 2008; FENG; WU, 2009; PERRON et al., 2010), possibilitando a escolha dentre vários tipos de veículos para atuar em um mesmo arco. Em um contexto global, diferentes modais 
de transporte são normalmente uma consequência natural das opções de transporte em todo o mundo: pelo ar, por mar ou por terra (MELO; NICKEL; SALDANHA-DA-GAMA, 2009).

Os custos de transporte são aplicados como variável de decisão nos modelos de Vidal e Goetschalckx (2001), Villegas e Ouenniche (2008), Perron et al. (2010), Papapostolou, Kondili e Kaldellis (2011), Sousa et al. (2011), Creazza, Dallari e Rossi (2012) e Singh et al. (2012). O que se percebe é que a utilização dessa variável tem aumentado nos trabalhos mais recentemente publicados, possibilitando inferir que está havendo uma ampliação e refinamento das abordagens previamente publicadas, o que qualifica e aproxima ainda mais esses modelos da realidade.

Os únicos modelos que incorporaram parâmetros e/ou variáveis de preço de transferência foram Vidal e Goetschalckx (2001), Villegas e Ouenniche (2008), Perron et al. (2010) e Susarla e Karimi (2012). O modelo de Vidal e Goetschalckx (2001) (e consequentemente em Perron et al. (2010)) seleciona simultaneamente os locais das instalações, calcula os fluxos entre elas, define os preços de transferência e aloca os custos de transporte para qualquer expedidor ou receptador, em todos os níveis da cadeia. Em Villegas e Ouenniche (2008), as variáveis de decisão são a quantidade de produtos comercializados, os preços de transferência e o custo de transporte entre os parceiros comerciais.

O número restrito de modelos que consideram preços de transferência na formulação do problema pode estar relacionado à não linearidade da função objetivo, causada por essa variável de decisão, tornando o problema mais difícil de ser solucionado. Entretanto, em modelos de otimização e desenho da cadeia de suprimentos global, aspectos como taxas corporativas e preços de transferência são de suma importância (MEIXELL; GARGEYA, 2005). Assim, observa-se através do cenário apresentado no Quadro 3 uma potencial fonte de pesquisas futuras, visto a necessidade de se adicionar essas variáveis a modelos de otimização e projeto da cadeia de suprimentos global.

Cabe destacar também que no modelo de Vila, Martel e Beauregard (2006) a variável layout das instalações é considerada como de decisão. Esse tipo de decisão é normalmente associado com a escolha de equipamentos ou tecnologias que comportam o processo produtivo, mas não são comuns nos modelos de desenho da cadeia de suprimentos global.

\subsection{Aspectos gerais dos modelos analisados}

Por aspectos gerais consideram-se a abordagem de modelagem utilizada, a abordagem de solução, o horizonte de planejamento (período simples ou multiperíodo), o número de níveis da cadeia e o contexto industrial em que os modelos foram aplicados. O Quadro 4 sumariza esses aspectos para os artigos selecionados. A abordagem de solução foi definida em dois grandes grupos, conforme classificação de Melo, Nickel e Saldanha-da-Gama (2009): "algoritmos específicos", quando a resolução do modelo contou com a utilização de algoritmos especialmente adaptados para tal fim; e "solução geral", resolvidos com softwares de programação matemática de uso geral, obtendo-se a solução ótima ou uma solução dentro de limites pré-especificados.

Com relação à abordagem de modelagem, tem-se a predominância de Programação Linear Inteira Mista (PLIM) e de Programação Linear (PL). A exceção é o modelo de Balaji e Viswanadham (2008), classificado como Programa Não Linear Inteiro Misto, desenvolvido para apoiar a decisão de produção própria ou terceirização nos vários estágios de uma cadeia de suprimentos global. Um algoritmo guloso, greedy strategy, é utilizado para solucionar o problema e uma cadeia de suprimentos fictícia de múltiplos estágios é proposta para validar o modelo. Aliás, essa é uma das limitações do estudo, visto que nem os dados, nem a cadeia desenhada para testar o modelo são reais, sendo necessário um cenário e um conjunto de dados mais realistas para verificar a sua robustez.

Algoritmos específicos também foram utilizados para solucionar problemas em Arntzen et al. (1995), Vidal e Goetschalckx (2001), Perron et al. (2010) e Sousa et al. (2011). Os demais modelos utilizaram a solução geral (ótima ou quase ótima) fornecida por softwares de otimização ou neles os problemas foram somente modelados e não resolvidos, como nos de Fandel e Stammen (2004), Villegas e Ouenniche (2008) e Creazza, Dallari e Rossi (2012).

Arntzen et al. (1995) desenvolveram uma PLIM para resolver o problema de desenho de uma multinacional fabricante de eletrônicos, a Digital Equipment Corporation. O modelo utilizou dados reais da cadeia de suprimentos global da empresa e recomendou um plano de reestruturação de 18 meses (e de cinco anos) para reduzir custos e melhorar o serviço ao cliente. Para a resolução, e obtenção da solução ótima, foi aplicada a heurística de row-factorization, aliada a enumeração branch-and-bound com tipos de ramos generalizados, para evitar atrasos no tempo de solução computacional. Entretanto, o método de solução não está totalmente descrito no artigo, sendo somente mencionado.

Vidal e Goetschalckx (2001) utilizam um modelo de PL que busca maximizar o lucro de uma multinacional depois dos impostos. A metodologia de solução é um algoritmo heurístico (heurística Alternate) que decompõe o modelo em um conjunto de subproblemas de PL e, em seguida, busca uma solução ideal ou satisfatória. Uma solução inicial viável é necessária 


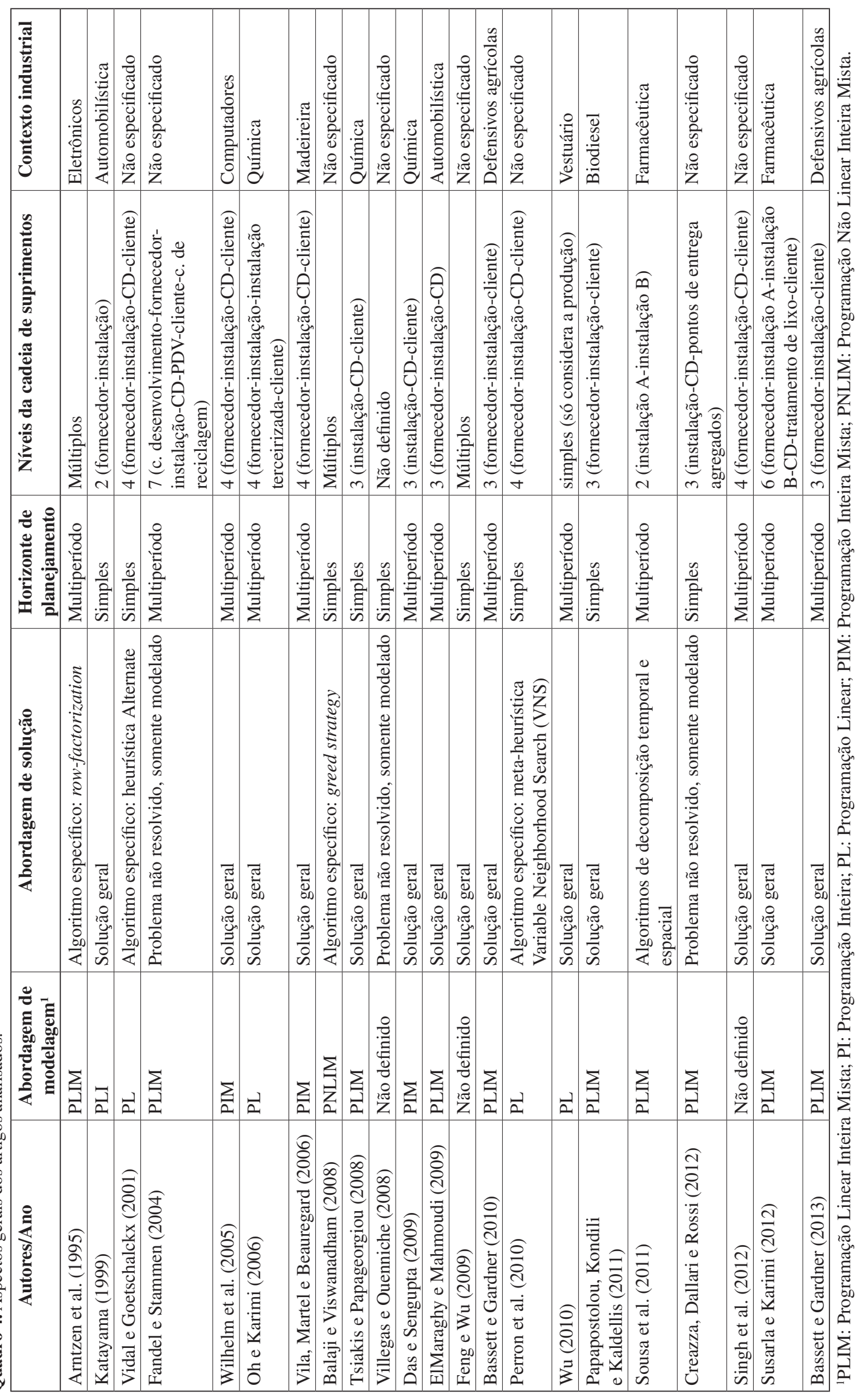


para iniciar a heurística. Vidal e Goetschalckx (2001) comparam sete processos de inicialização diferentes para o problema proposto. Os autores avaliaram a heurística com instâncias aleatórias, sem baseá-las em uma indústria específica.

Perron et al. (2010) propõem uma reformulação do modelo de Vidal e Goetschalckx (2001) que reduz em pelo menos $65 \%$ o número de termos bilineares. Os autores adotam a meta-heurística Variable Neighborhood Search (VNS). A VNS é baseada na ideia de mudança sistemática do "bairro" durante a busca, a fim de se obter um local ideal que, em oposição a um método de busca local (heurística Alternate), não é dependente da solução inicial. Duas implementações da VNS são apresentadas: uma aplicação geral, concebida para qualquer modelo bilinear (já utilizada por Audet et al. (2004)), e uma nova aplicação projetada especificamente para o problema proposto. O desempenho das três heurísticas (Alternate e duas VNS) é comparado utilizando-se instâncias aleatórias. Os resultados indicam que a nova implementação da VNS específica supera as outras duas heurísticas: (i) a VNS geral nunca obtém solução melhor que a VNS específica e geralmente é mais lenta; (ii) a VNS específica aprimorou a melhor solução encontrada pela heurística Alternate em mais de 50\% dos casos, em todas as instâncias, e em mais de $89 \%$ dos casos nos quais era possível uma melhoria (isto é, instâncias em que a Alternate não encontrou ou não poderia encontrar a solução ótima). Ainda, Perron et al. (2010) conseguem, através da VNS específica, obter a solução ótima para todas as pequenas instâncias testadas e para $26 \%$ das instâncias médias, melhorando significativamente os resultados encontrados por Vidal e Goetschalckx (2001) através da heurística Alternate.

Sousa et al. (2011) apresentam um modelo multiperíodo que não é passível de resolução em tempo computacional aceitável para grandes instâncias. Dessa forma, eles utilizam dois métodos de decomposição: o primeiro consiste em separar a cadeia de suprimentos global em dois níveis (decomposição espacial) e o segundo decompõe o modelo em vários subproblemas independentes, um para cada período de tempo (decomposição temporal). A decomposição espacial possibilitou melhores resultados para a otimização do problema do que a decomposição temporal, entretanto possui tempo computacional mais elevado.

Referente ao horizonte de planejamento, dentre os modelos analisados a maioria é multiperíodo. Em Fandel e Stammen (2004) são utilizados aspectos dinâmicos, aplicando-se uma estrutura de tempo em dois períodos, macro (períodos longos de tempo, como anos) e micro (trimestres ou meses). Os parâmetros de processo de desenvolvimento do produto, preços de transferência, custos e outros parâmetros financeiros são determinados em macroperíodos. Já os preços de venda, capacidade e demanda do fluxo de material são fixados em microperíodos. Em Wilhelm et al. (2005), os períodos são fixados em seis ou 12 meses; Oh e Karimi (2006) utilizam períodos curtos de tempo em um intervalo de um ano; Vila, Martel e Beauregard (2006), ElMaraghy e Mahmoudi (2009) e Wu (2010) consideram períodos de quatro meses dentro de um ano. Susarla e Karimi (2012) analisam um horizonte de planejamento de 60 meses, com 20 períodos trimestrais, indicando ao final de cada trimestre a quantidade de produto demandada. No modelo de Das e Sengupta (2009), no nível estratégico são considerados períodos de um ano e no nível operacional, períodos de um dia. A utilização de modelos multiperíodo, em relação aos de período simples, é o que se apresenta mais adequado a problemas de desenho da cadeia de suprimentos global, visto a necessidade de captar variações de demanda, preços de mercado, custos, fretes, seguros etc.

No que tange à análise do número de níveis da cadeia de suprimentos, observa-se a predominância de problemas com três e quatro níveis. Os mais comumente utilizados são fornecedores, instalações, centros de distribuição e clientes. Entretanto, no modelo de Creazza, Dallari e Rossi (2012) os três níveis são instalação, $\mathrm{CD}$ e pontos de entrega agregados, sendo esse definido como macrogrupos ou clusters formados a partir dos milhares pontos de entrega que possui uma companhia multinacional. Já em Susarla e Karimi (2012), dentre os seis níveis estão as instalações para tratamento do lixo de multinacionais da indústria farmacêutica, aspecto não considerado por nenhum outro trabalho analisado. Nos modelos de Arntzen et al. (1995) e de Feng e Wu (2009) múltiplos níveis são utilizados, mas não há a descrição da composição dos níveis; em Villegas e Ouenniche (2008) não há a definição do número de níveis e $\mathrm{Wu}$ (2010) considera apenas a produção, objetivando minimizar os custos de produção. O problema de Fandel e Stammen (2004) possui o maior número de níveis declarados, sete (centro de desenvolvimento, fornecedor, instalação, $\mathrm{CD}$, ponto de venda, cliente, centro de reciclagem). Entretanto, faltam testes empíricos nesse modelo, visto que ele foi somente modelado, não se comprovando a existência de solução viável. Os autores também não indicam nenhum procedimento de solução específico.

Quanto ao contexto industrial, percebe-se em muitos modelos a inexistência de aplicação ao ambiente real (VIDAL; GOETSCHALCKX, 2001; FANDEL; STAMMEN, 2004; BALAJI; VISWANADHAM, 2008; VILLEGAS; OUENNICHE, 2008; FENG; WU, 2009; PERRON et al., 2010; CREAZZA; DALLARI; ROSSI, 2012; SINGH et al., 2012). Já em trabalhos como os de Katayama (1999), Wilhelm et al. (2005), Oh e Karimi (2006), Vila, Martel e Beauregard (2006) e Sousa et al. (2011) houve a modelagem para a 
cadeia de suprimentos global de determinada indústria foco, mas os dados foram gerados aleatoriamente, sem fazer uso da base de dados das organizações pertencentes à rede. Em Das e Sengupta (2009) há o desenvolvimento de uma aplicação prática, referenciando uma unidade estratégica asiática de uma indústria de gases e fertilizantes químicos. Esses autores utilizam o modelo desenvolvido em diferentes cenários, com dados gerados aleatoriamente, que variam em conformidade com os dados operacionais da empresa base. Os resultados da análise de sensibilidade indicam que a saída do modelo é bastante sensível ao custo de entrada de recursos e o modelo pode ser considerado adequado para o problema discutido.

Exceções são os trabalhos de Arntzen et al. (1995), Tsiakis e Papageorgiou (2008), ElMaraghy e Mahmoudi (2009), Bassett e Gardner (2010, 2013), Wu (2010) e Papapostolou, Kondili e Kaldellis (2011), que utilizam dados históricos das empresas estudadas para validar os modelos desenvolvidos. Em Tsiakis e Papageorgiou (2008), o problema considera uma indústria do setor químico. Dados do Enterprise Resource Planning (ERP) da organização foram utilizados para testar o modelo. Quatro cenários são propostos, indicando economias quando da aplicação do modelo em relação ao estado atual. Essa economia é significativa para justificar o redesenho da cadeia de suprimentos em conformidade com os resultados obtidos no projeto. Os benefícios observados são um melhor aproveitamento das fábricas, seleção de portfólios de produtos adequados, economia no transporte total e em impostos.

Relativo aos trabalhos de Bassett e Gardner (2010, 2013), o primeiro valida o modelo considerando uma família de produtos de defensivos agrícolas; a partir dessa validação, no segundo trabalho, uma situação real é analisada e o modelo é aplicado para um produto da cadeia de suprimentos global, indicando melhora significativa na eficiência e rentabilidade. Em Wu (2010), para validar a eficácia do modelo, uma série de experimentos computacionais (seis cenários) são realizados com base nos dados fornecidos por uma indústria de vestuário. Dentro de um ano, são selecionados períodos de três meses (estações do ano). Uma limitação desse estudo é que só analisa o nível de produção da indústria, negligenciando as implicações de desempenho de outros atores da rede, como fornecedores de bens e serviços, dentro do contexto global da cadeia de suprimentos. Papapostolou, Kondili e Kaldellis (2011) testam o modelo em uma cadeia de biodiesel grega, mas salientam que encontraram como ponto crítico para a implementação da abordagem a dificuldade para identificar informações quantitativas confiáveis dos vários parâmetros do problema.

Pesquisas baseadas em problemas empíricos vivenciados pelas indústrias, no projeto da cadeia de suprimentos, ainda são escassos e carecem de maior exploração. A modelagem de problemas de natureza real pode fornecer contribuições práticas à gestão organizacional.

\subsection{Aspectos internacionais destacados nos artigos analisados}

A globalização econômica criou novas oportunidades para as empresas ampliarem seus negócios de comercialização de produtos e oferecerem serviços em todo o mundo. Como consequência dessa evolução, modelos destinados à cadeia de suprimentos global têm ganhado importância crescente (MELO; NICKEL; SALDANHA-DA-GAMA, 2009). Tais modelos possuem características globais comuns a um cenário internacional, no qual as atividades de uma empresa são geograficamente dispersas entre vários países. No Quadro 5 são apresentados os aspectos internacionais considerados na modelagem dos problemas dos artigos analisados.

Além dos aspectos destacados no Quadro 5, cabe ressaltar que, com exceção dos trabalhos Katayama (1999), Wilhelm et al. (2005), Wu (2010) e Susarla e Karimi (2012), os demais avaliam o impacto do custo de transporte na modelagem da cadeia de suprimentos global. Entretanto, somente Arntzen et al. (1995), Vidal e Goetschalckx (2001), Wilhelm et al. (2005) e Perron et al. (2010) incorporam o tempo em trânsito em termos de custos.

Impostos e taxas de importação e exportação são abordados em praticamente todos os modelos analisados, exceto em ElMaraghy e Mahmoudi (2009) e Wu (2010). Entretanto, não há a descrição específica desses impostos e taxas, abarcando-os como um valor ou porcentagem total, inserido nos custos da cadeia. Aliás, ElMaraghy e Mahmoudi (2009) analisam apenas a variação na taxa de câmbio. O objetivo do modelo é minimizar os custos totais da cadeia ao longo do tempo. A sua aplicação é avaliada usando dados históricos de um fabricante de limpadores de motor para automóveis, com fábricas e CDs localizados na Ásia, América do Norte e Europa. Uma das aplicações do modelo é analisar o impacto de variações na taxa de câmbio em cada nó da rede para a ótima configuração da cadeia de suprimentos global.

Outro modelo que considera apenas um aspecto internacional, dentre os destacados no Quadro 5, é o de Wu (2010), que insere na análise quotas de importação. Wu (2010) estuda problemas de carga de produção na cadeia de suprimentos global, em que o limite de quota de importação é aplicado para as empresas que distribuem tarefas entre as diferentes plantas de produção na China com o objetivo de satisfazer mercados de demanda norteamericanos e europeus buscando minimizar o custo 


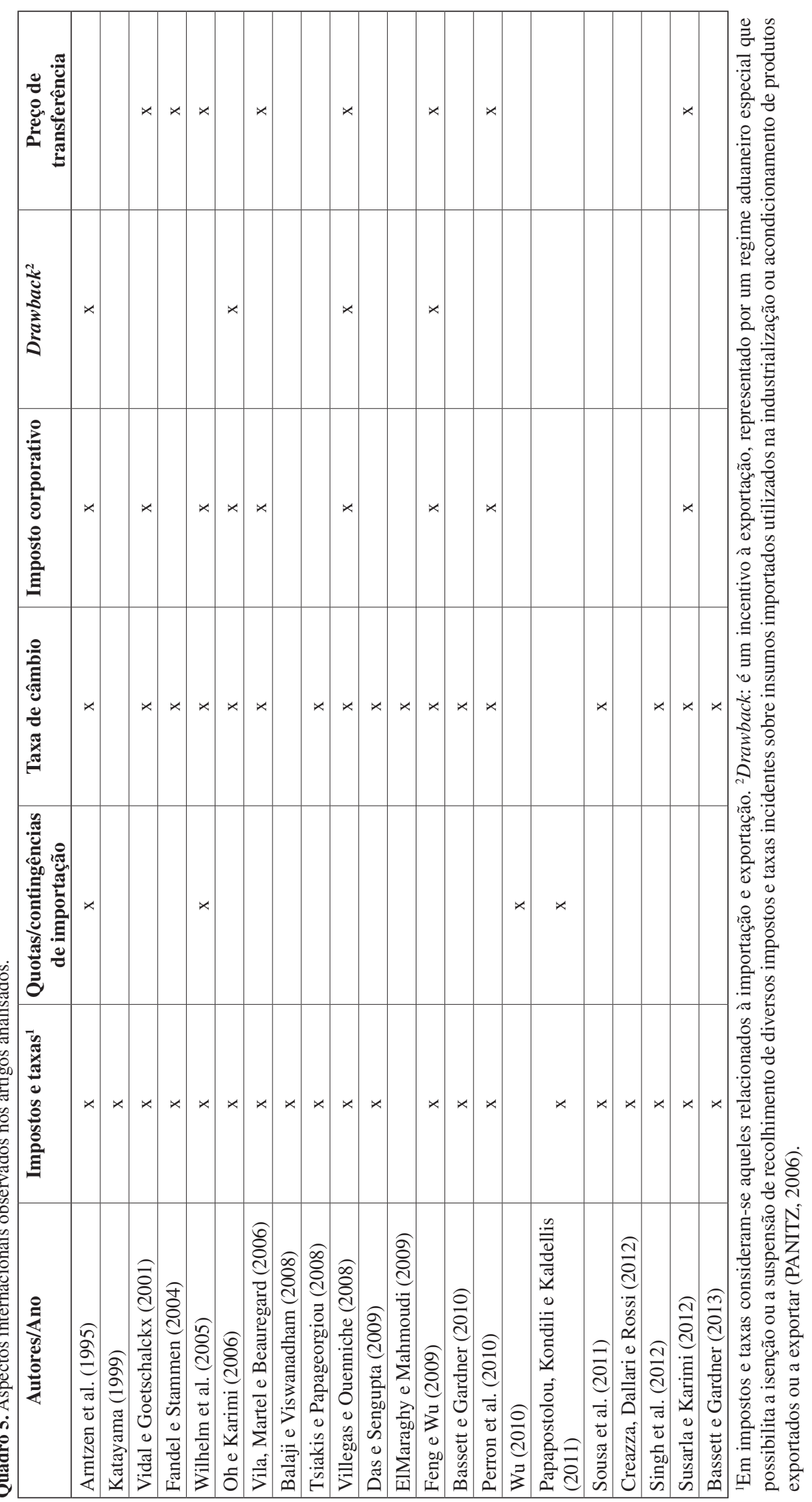


total de produção. Entre os resultados do modelo pode-se obter a quantidade de produção, nível de força de trabalho, horas extras dos trabalhadores, utilização da capacidade das máquinas regulares, capacidade das máquinas adicionais, utilização de trabalhadores qualificados e de trabalhadores não qualificados, quantidade de matéria-prima para estoque e excesso de contingente. Outros modelos que abordam contingências de importação específicas são Arntzen et al. (1995), Wilhelm et al. (2005) e Papapostolou, Kondili e Kaldellis (2011).

Parâmetros de taxa de câmbio para converter moedas nacionais em uma moeda comum (geralmente dólar) são aplicados na grande maioria dos trabalhos analisados, com exceção dos de Katayama (1999), Balaji e Viswanadham (2008), Wu (2010), Papapostolou, Kondili e Kaldellis (2011) e Creazza, Dallari e Rossi (2012). Considerar a taxa de câmbio na conversão para uma moeda única de custos com fornecedores, fabricantes e mercados faz-se necessário, visto que embora a variação cambial possa ser sutil em curto prazo, torna-se significativa no longo prazo e tende a afetar decisões estratégicas da cadeia de suprimentos global (ELMARAGHY; MAHMOUDI, 2009). Papapostolou, Kondili e Kaldellis (2011) utilizam somente euros como moeda de parâmetro do modelo, visto que a cadeia global analisada limita-se a países participantes da zona do euro. Além disso, no modelo não são introduzidos impostos e taxas internacionais específicas, pois, conforme os autores, esses tributos já estão incluídos no custo da matéria-prima e do produto acabado.

Com relação aos impostos corporativos, menos da metade dos trabalhos analisados incluiu esses aspectos (ARNTZEN et al., 1995; VIDAL; GOETSCHALCKX, 2001; WILHELM et al., 2005; OH; KARIMI, 2006; VILA; MARTEL; BEAUREGARD, 2006; VILLEGAS; OUENNICHE, 2008; FENG; WU, 2009; PERRON et al., 2010; SUSARLA; KARIMI; 2012) referentes ao imposto de renda ou sobre o capital, cobrado das subsidiárias, com tributação variável conforme o país. O que se percebe é que os estudos mais recentes não estão contemplando esses impostos explicitamente, o que contrasta com os trabalhos publicados no início da década de 2000 e sugere um interessante campo de investigação.

No que tange economias de drawback, são poucos os modelos que as incorporam (ARNTZEN et al., 1995; OH; KARIMI, 2006; VILLEGAS; OUENNICHE, 2008; FENG; WU, 2009). Oh e Karimi (2006) defendem que o valor que pode ser poupado através da devolução dos direitos de drawback reclamados pode chegar a milhões de dólares. Em vista da importância de se considerar esse aspecto internacional no projeto da cadeia de suprimentos, os autores desenvolveram um modelo de programação linear abordando três fatores regulatórios: impostos corporativos, taxas de importação e drawbacks. Segundo Oh e Karimi (2006), a incorporação desses três fatores é um diferencial do modelo, além de considerar o contexto multiprodutos para o cálculo dos direitos de drawback. O modelo é resolvido com base em dois cenários. O cenário 1 incluiu os três fatores regulatórios; enquanto o cenário 2 ignora o drawback. Um resultado interessante encontrado é que somente nos casos em que o drawback torna a matéria-prima importada mais competitiva em relação às domésticas faz sentido para uma instalação consumir mais materiais importados, senão o melhor é utilizar somente matéria-prima doméstica. Entretanto, esse modelo não é generalizado, sendo resolvido com dados aleatórios em uma cadeia restrita.

Villegas e Ouenniche (2008) também incorporam drawbacks. Os autores propõem um modelo da cadeia de suprimentos global que também considera os custos de produção, custos de transporte, sanções relacionadas à manipulação ilegal de preços de transferência, a exposição ao risco de câmbio, tarifas, royalties e dividendos e taxas de impostos corporativos. O modelo possui os seguintes atributos; (i) faz uma diferença explícita entre decisões de importação e de exportação, o que leva a conclusões diferentes; (ii) incorpora as decisões de alocação de custos de transporte e restituição de taxas alfandegárias na análise; (iii) inclui um tratamento detalhado de taxas diferenciadas de impostos e créditos fiscais; e (iv) trabalha com qualquer número de produtos, divisões, mercados e países. Formulou-se o problema como um programa sem restrições matemáticas, sem aplicação a um contexto real, o que pode limitar a aplicação do modelo.

No que tange ao preço de transferência, oito modelos o incluem na composição dos custos da cadeia (VIDAL; GOETSCHALCKX, 2001; FANDEL; STAMMEN, 2004; WILHELM et al., 2005; VILA; MARTEL; BEAUREGARD, 2006; VILLEGAS; OUENNICHE, 2008; FENG; WU, 2009; PERRON et al., 2010; SUSARLA; KARIMI, 2012). Tendo em vista que a determinação dos preços de transferência entre as subsidiárias de uma multinacional é uma das questões mais importantes da cadeia de suprimentos global (GOETSCHALCKX; VIDAL; DOGAN, 2002), pode-se considerar baixo o índice de modelos que incorporam esse fator. Conforme Nieckels (1976), pequenas mudanças nos preços de transferência podem levar a diferenças significativas no lucro líquido da multinacional. Nesse mesmo sentido, Miller e De Matta (2008) afirmam que ao definir o preço de transferência ideal a matriz pode tirar proveito das diferenças entre as taxas de recolhimento dos países onde se localizam as subsidiárias.

Em um modelo bastante abrangente em termos de aspectos internacionais incorporados, Wilhelm et al. 
(2005) abordam restrições de lista de materiais (bill-of-material), considerações financeiras internacionais e dos fluxos de materiais através da cadeia de suprimentos, utilizando dispositivos eficazes de modelagem (por exemplo, aplicando técnicas de linearização em termos de não linearidades que surgem na modelagem de preços de transferência e nos custos de transporte). Como questões típicas internacionais são utilizados contingências de importação, preços de transferência, impostos corporativos, taxas de câmbio, bem como características únicas do NAFTA. Para testar o modelo, custos são gerados aleatoriamente para um período de três anos.

O que se percebe através dessa discussão é que os modelos que consideram um maior número de aspectos internacionais são, geralmente, aqueles que não têm aplicação ao ambiente real ou apresentam dados gerados aleatoriamente, sem fazer uso de dados históricos de empresas participantes da cadeia de suprimentos modelada. Esses modelos, por serem mais genéricos, permitem aos investigadores centrarem-se em características internacionais mais complexas de serem inseridas, possibilitando o desenvolvimento de novos métodos de solução para os modelos propostos.

\section{Considerações finais e oportunidades para pesquisas futuras}

Através da discussão teórica realizada pode-se perceber questões emergentes na modelagem do projeto da cadeia de suprimentos global, indicando oportunidades e necessidades de desenvolvimento de novos modelos e técnicas de solução para ajudar no processo de tomada de decisão nesse âmbito. Frente às considerações realizadas no decorrer deste trabalho, listam-se alguns aspectos que podem ser aprimorados em pesquisas futuras.

A integração de decisões da cadeia de suprimentos global de nível estratégico e operacional desponta como uma potencial fonte de investigação. Somente o trabalho de Das e Sengupta (2009) aliou esses dois níveis para a tomada de decisão. Ao se trabalhar com modelos integrados, podem-se desenvolver planos de ação que abarquem decisões de nível macro, como, por exemplo, aquelas relacionadas às incertezas decorrentes de regulamentos governamentais, questões internacionais, localização e seleção de instalações; e de nível micro, como distribuição e transporte do produto acabado aos clientes. Esse aspecto também é ressaltado por Meixell e Gargeya (2005), os quais afirmam que embora o desempenho da cadeia de suprimentos global tenha ampliado o seu escopo, a comunidade acadêmica ainda não deu a devida atenção a objetivos alternativos.

Nesse mesmo sentido, observou-se que poucos trabalhos integram decisões internas (p. ex.: variáveis de quantidade de produto acabado e localização de instalações) e externas (ex. variáveis de aquisição de matéria-prima e seleção de fornecedores). Visto que fornecedores são atores atuantes na cadeia, é interessante que se adicionem objetivos ou restrições para avaliar características como quantidade mínima de fornecedores, restrições orçamentárias, preferências geográficas de localização de fornecedores, entre outras, propiciando um desenho mais realista da cadeia global.

O acréscimo de variáveis de natureza estocástica em modelos de cunho predominantemente determinístico como os aqui descritos também complementaria a qualidade em futuros trabalhos, visto que a maioria dos estudos supõe que as características e os parâmetros de projeto da cadeia tanto a nível estratégico quanto operacional são determinísticos (SANTOSO et al., 2005). Nas cadeias de suprimento global, que podem incluir centenas de empresas com várias camadas de fornecedores e clientes intermediários, existem inúmeros riscos para analisar e resolver (GOH; LIM; MENG, 2007), dentre eles o risco de fornecimento, o risco de demanda e o risco de crédito comercial, que ao serem analisados respeitando-se as características incertas que os permeiam tendem a fornecer análises mais fidedignas do cenário modelado. Em ElMaraghy e Mahmoudi (2009), por exemplo, quantidade demandada e o lead-time de produção e transporte são considerados fixos, não respeitando a natureza randômica desses fatores. Compreende-se que há um aumento na complexidade de resolução do problema ao se acrescentar a estocasticidade, mas a adoção desses fatores traria uma representação mais fidedigna da realidade ao modelo proposto.

A aplicação de horizontes de planejamento multiperíodo também reflete com mais propriedade o desenho da cadeia de suprimentos global, tanto que muitos dos modelos analisados já incluem essa característica. Gupta e Maranas (2001) afirmam que a variabilidade na demanda do produto, por exemplo, deve estar alocada na modelagem do planejamento da cadeia de suprimentos, levando em consideração períodos futuros de tempo, a partir de informações atuais. Entretanto, conforme os autores, um dos componentes-chave ainda pouco explorado na literatura é a eficácia das políticas de planejamento em vários horizontes de tempo, o que reflete um cenário real de planejamento multiperíodo. Além disso, decisões de aquisição e implementação, por exemplo, têm efeitos no longo prazo e sua análise deve ser estendida por vários períodos de tempo.

A inclusão de preços de transferência é outro fator que deve ser considerado no projeto da cadeia de suprimentos global. Esse é, dentre os aspectos internacionais abordados no Quadro 5, um dos mais importantes, visto que pode influenciar 
consideravelmente na rentabilidade da multinacional. O que se percebe através das análises realizadas é que a maioria dos modelos que aborda esse fator é projetada para horizontes de tempo simples, outros são apenas modelados e não aplicados à realidade industrial. Isso sugere que a inclusão dos preços de transferência nos modelos de desenho da cadeia de suprimentos global induz simplificações neles, o que indica a necessidade de melhor representação da realidade em modelos futuros.

Outro fator bastante relevante é a investigação de cenários práticos. $\mathrm{O}$ desafio que se tem é decidir sobre quais recursos do ambiente real modelar a fim de reproduzir com maior fidedignidade o cenário investigado e manter o problema tratável. O uso de dados e cenários reais é uma necessidade e uma oportunidade que desponta para futuros modelos de projeto da cadeia de suprimentos global. Entretanto, ao assumir cenários reais, tem-se um aumento considerável na complexidade do problema, o que poderia impossibilitar a resolução através de métodos de solução exatos, sistemática mais amplamente adotada, conforme observado no Quadro 4. Problemas de grande complexidade, segundo Shapiro (2007), só podem ser resolvidos com rigorosos programas matemáticos eficientemente combinados com métodos (meta)heurísticos. Assim, métodos de solução computacional especializados (heurísticas/metaheurísticas) poderiam ser desenvolvidos a fim de aprimorar a busca de melhores soluções. Shapiro (2007) cita alguns métodos que podem ser utilizados em conjunto a fim de se atingir esse objetivo:

- Métodos de decomposição podem ser aplicados a programas de grande escala, isolando submodelos que podem ser eficientemente resolvidos através de (meta)heurísticas. Um exemplo da aplicação dessa técnica é descrito em Sousa et al. (2011).

- Heurísticas podem proporcionar bons subplanos para iniciar-se a resolução de problemas.

- Heurísticas podem ser usadas para modificar ou ampliar os subplanos computados por submodelos lagrangeanos.

A integração de (meta)heurísticas a outros métodos de solução traz a vantagem de se poder solucionar problemas de grande escala em um período de tempo razoável. Ainda, na opinião de Holmström (2004), caso um problema de cadeia de suprimentos consiga traduzir parte do mundo real e torne-se difícil de resolver, um potencial ponto de partida é a utilização de heurísticas.

Finalmente, cabe ressaltar a necessidade do desenvolvimento de ferramentas de mapeamento de dados, visto que, conforme Papapostolou, Kondili e Kaldellis (2011), a principal dificuldade para validar os modelos de otimização da cadeia de suprimentos global é a obtenção dos dados quantitativos relativos aos vários parâmetros definidos. Dentre todos os artigos analisados, somente Creazza, Dallari e Rossi (2012) fornecem orientações metodológicas para a obtenção e processamento dos dados necessários para configurar e executar o modelo proposto.

As oportunidades de pesquisa aqui elencadas visam contribuir para o aprimoramento e desenvolvimento de futuros modelos. Essas considerações possibilitam que alguns aspectos ainda pouco abordados ou negligenciados possam ser trabalhados em modelos para o projeto da cadeia de suprimentos global, colaborando para a maturidade desse campo de pesquisa.

\section{Agradecimentos}

Os autores agradecem à Capes e ao CNPq pelo apoio financeiro.

\section{Referências}

ARNTZEN, B. C. et al. Global Supply Chain Management at Digital Equipment Corporation. Interfaces, v. 25, n. 1, p. 69-93, 1995. http://dx.doi.org/10.1287/inte.25.1.69

AUDET, C. et al. Pooling problem: Alternate formulations and solution methods. Management Science, v. 50, n. 6, p. 761-776, 2004. http://dx.doi.org/10.1287/ mnsc. 1030.0207

BAGHALIAN, A.; REZAPOUR, S.; FARAHANI, R. Z. Robust supply chain network design with service level against disruptions and demand uncertainties: A real-life case. European Journal of Operational Research, v. 227, p. 199-215, 2013. http://dx.doi.org/10.1016/j. ejor.2012.12.017

BALAJI, K.; VISWANADHAM, N. A Tax Integrated Approach for Global Supply Chain Network Planning. IEEE Transactions on Automation Science and Engineering, v. 5, n. 4, p. 587-596, 2008. http://dx.doi. org/10.1109/TASE.2008.923823

BASSETT, M.; GARDNER, L. Optimizing the design of global supply chains at Dow AgroSciences. Computers \& Chemical Engineering, v. 34, n. 2, p. 254-265, 2010. http://dx.doi.org/10.1016/j.compchemeng.2009.08.002

BASSETT, M.; GARDNER, L. Designing optimal global supply chains at Dow AgroSciences. Annals of Operations Research, v. 203, p. 187-216, 2013. http://dx.doi.org/10.1007/s10479-010-0802-2

CREAZZA, A.; DALLARI, F.; ROSSI, T. An integrated model for designing and optimising an international logistics network. International Journal of Production Research, v. 50, n. 11, p. 2925-2939, 2012. http://dx.doi. org/10.1080/00207543.2011.578157

DAS, K.; SENGUPTA, S. A hierarchical process industry production-distribution planning model. International Journal of Production Economics, v. 117, n. 2, p. 402-419, 2009. http://dx.doi.org/10.1016/j. ijpe.2008.12.003

ELMARAGHY, H. A; MAHMOUDI, N. Concurrent design of product modules structure and global supply chain configurations. International Journal of Computer 
Integrated Manufacturing, v. 22, n. 6, p. 483-493, 2009. http://dx.doi.org/10.1080/09511920802389553

FANDEL, G.; STAMMEN, M. A general model for extended strategic supply chain management with emphasis on product life cycles including development and recycling. International Journal of Production Economics, v. 89, n. 3, p. 293-308, 2004. http://dx.doi. org/10.1016/S0925-5273(03)00198-1

FENG, C.-M.; WU, P. J. A tax savings model for the emerging global manufacturing network. International Journal of Production Economics, v. 122, n. 2, p. 534-546, 2009. http://dx.doi.org/10.1016/j.ijpe.2009.05.019

GOETSCHALCKX, M.; VIDAL, J.; DOGAN, K. Modeling and design of global logistics systems: A review of integrated strategic and tactical models and design algorithms. European Journal of Operational Research, v. 143, n. 1, p. 1-18, 2002. http://dx.doi. org/10.1016/S0377-2217(02)00142-X

GOH, M. LIM, J.; MENG, F. A stochastic model for risk management in global supply chain networks. European Journal of Operational Research, v. 182, n. 1 , p. 164-173, 2007. http://dx.doi.org/10.1016/j. ejor.2006.08.028

GUPTA, A.; MARANAS, C. D. Multiperiod Planning of Multisite Supply Chains Under Demand. European Symposium on Computer Aided Process Engineering, p. 871-876, 2001.

HOLMSTRÖM, J. Solution Design as a heuristic for conducting explorative supply chain research. 2004 . Thesis (Doctorate)-Helsinki University of Technology, Helsinki, 2004.

KATAYAMA, H. Design of a global car productionlogistics system for a future ASEAN-China region. International Journal of Operations \& Production Management, v. 19, n. 5-6, p. 582-603, 1999. http:// dx.doi.org/10.1108/01443579910260892

MEIXELL, M.; GARGEYA, V. Global supply chain design: A literature review and critique. Transportation Research Part E: Logistics and Transportation Review, v. 41, n. 6, p. 531-550, 2005. http://dx.doi.org/10.1016/j. tre.2005.06.003

MELO, M.; NICKEL, S.; SALDANHA-DA-GAMA, F. Facility location and supply chain management - A review. European Journal of Operational Research, v. 196, n. 2, p. 401-412, 2009. http://dx.doi.org/10.1016/j. ejor.2008.05.007

MENTZER, J. T.; STANK, T. P.; MYERS, M. B. Why Global Chain Management? In: MENTZER, J. T.; MYERS, M. B.; STANK, T. P. (Eds.). Handbook of Global Supply Management. Thousand Oaks: Sage Publications, 2007. p. 1-15. http://dx.doi.org/10.4135/9781412976169.n1

MILLER, T.; DE MATTA, R. A Global Supply Chain Profit Maximization and Transfer Pricing Model. Journal of Business Logistics, v. 29, n. 1, 2008. http://dx.doi. org/10.1002/j.2158-1592.2008.tb00074.x

MULA, J. et al. Mathematical programming models for supply chain production and transport planning. European Journal of Operational Research, v. 204, n. 3, p. 377-390, 2010. http://dx.doi.org/10.1016/j. ejor.2009.09.008
NIECKELS, L. Transfer Pricing in Multinational Firms: A Heuristic Programming Approach and a Case Study. John Wiley and Sons: New York, 1976.

OH, H. C.; KARIMI, I. A. Global multiproduct productionDistribution planning with duty drawbacks. AIChE Journal, v. 52, n. 2, p. 595-610, 2006. http://dx.doi. org/10.1002/aic.10669

OLSON, J. E. Top-25-Business-School Professors Rate Journals in Operations Management and Related Fields. Interfaces, v. 35, n. 4, p. 323-338, 2005. http://dx.doi. org/10.1287/inte.1050.0149

PANITZ, C. E. Dicionário de Logística. 2006. Disponível em: <http://www.nucleodelogistica.com.br/download/ dicionario_logistica_v1.3c.pdf $>$. Acesso em: 10 maio 2011.

PAPAPOSTOLOU, C.; KONDILI, E.; KALDELLIS, J. K. Development and implementation of an optimisation model for biofuels supply chain. Energy, v. 36, p. 6019-6026, 2011. http://dx.doi.org/10.1016/j. energy.2011.08.013

PERRON, S. et al. Exact and heuristic solutions of the global supply chain problem with transfer pricing. European Journal of Operational Research, v. 202, n. 3, p. 864-879, 2010. http://dx.doi.org/10.1016/j. ejor.2009.06.018

RUDBERG, M.; WEST, B. M. Global operations strategy: Coordinating manufacturing networks. Omega, v. 36, n. 1, p. 91-106, 2008. http://dx.doi.org/10.1016/j. omega.2005.10.008

SANTOSO, T. et al. A stochastic programming approach for supply chain network design under uncertainty. European Journal of Operational Research, v. 167, n. 1, p. 96-115, 2005. http://dx.doi.org/10.1016/j. ejor.2004.01.046

SCHMIDT, G.; WILHELM, W. Strategic, tactical and operational decisions in multi-national logistics networks: A review and discussion of modeling issues. International Journal of Production Research, v. 38, n. 7, p. 1501-1523, 2000. http://dx.doi. org/10.1080/002075400188690

SHAPIRO, J. F. Modeling the Supply Chain. 2. ed. Belmont: Thomson, 2007.

SINGH, A. R. et al. Design of global supply chain network with operational risks. The International Journal of Advanced Manufacturing Technology, v. 60, p. 273-290, 2012. http://dx.doi.org/10.1007/ s00170-011-3615-9

SOUSA, R. T. et al. Global supply chain planning for pharmaceuticals. Chemical Engineering Research and Design, v. 89, p. 2396-2409, 2011. http://dx.doi. org/10.1016/j.cherd.2011.04.005

STREHL, L. O fator de impacto do ISI e a avaliação da produção científica: aspectos conceituais e metodológicos. Ciência da Informação, v. 34, n. 1, 2005. http://dx.doi. org/10.1590/S0100-19652005000100003

SUSARLA, N.; KARIMI, I. A. Integrated supply chain planning for multinational pharmaceutical enterprises. Computers and Chemical Engineering, v. 42, p. 168-177, 2012. http://dx.doi.org/10.1016/j. compchemeng.2012.03.002 
TESTA, J. The Thomson Reuters Journal selection process. 2009. Disponível em: <http://wokinfo.com/ essays/journal-selection-process/>. Acesso em: 16 jun. 2013.

TEZZA, R.; BORNIA, A. C.; VEY, I. H. Sistemas de medição de desempenho: uma revisão e classificação da literatura. Gestão \& Produção, v. 17, n. 1, p. 75-93, 2010. http:// dx.doi.org/10.1590/S0104-530X2010000100007

TSIAKIS, P.; PAPAGEORGIOU, L. Optimal production allocation and distribution supply chain networks. International Journal of Production Economics, v. 111, n. 2, p. 468-483, 2008. http://dx.doi.org/10.1016/j. ijpe.2007.02.035

VERTER, V.; DINCER, M. C. Facility location and capacity acquisition: an integrated approach. Naval Research Logistics Quarterly, v. 42, p. 1141-1160, 1995a. http:// dx.doi.org/10.1002/1520-6750(199512)42:8<1141::AIDNAV3220420803>3.0.CO;2-B

VERTER, V.; DINCER, M. C. Global manufacturing strategy. In: DREZNER, Z. (Ed.). Facility Location: A Survey of Applications and Methods. New York: Springer-Verlag, 1995b. http://dx.doi. org/10.1007/978-1-4612-5355-6_13

VIDAL, C.; GOETSCHALCKX, M. A global supply chain model with transfer pricing and transportation cost allocation. European Journal of Operational Research, v. 129, n. 1, p. 134-158, 2001. http://dx.doi. org/10.1016/S0377-2217(99)00431-2
VIDAL, C.; GOETSCHALCKX, M. Strategic productiondistribution models: A critical review with emphasis on global supply chain models. European Journal of Operational Research, v. 98, n. 1, p. 1-18, 1997. http:// dx.doi.org/10.1016/S0377-2217(97)80080-X

VILA, D.; MARTEL, A.; BEAUREGARD, R. Designing logistics networks in divergent process industries: A methodology and its application to the lumber industry. International Journal of Production Economics, v. 102, n. 2, p. 358-378, 2006. http://dx.doi.org/10.1016/j. ijpe.2005.03.011

VILLEGAS, F.; OUENNICHE, J. A general unconstrained model for transfer pricing in multinational supply chains. European Journal of Operational Research, v. 187, n. 3, p. 829-856, 2008. http://dx.doi.org/10.1016/j. ejor.2006.04.048

WILHELM, W. et al. Design of international assembly systems and their supply chains under NAFTA. Transportation Research Part E: Logistics and Transportation Review, v. 41, n. 6, p. 467-493, 2005. http://dx.doi.org/10.1016/j.tre.2005.06.002

WU, Y. A time staged linear programming model for production loading problems with import quota limit in a global supply chain. Computers \& Industrial Engineering, v. 59, n. 4, p. 520-529, 2010. http://dx.doi. org/10.1016/j.cie.2010.06.007 